\title{
Does nitrogen source influence cadmium distribution in Arabidopsis plants?
}

\author{
Analía Vazquez $^{\mathrm{a}, 1}$, Laura Recalde ${ }^{\mathrm{c}, 1}$, Andrea Cabrera ${ }^{\mathrm{c}}$, María Daniela Groppa ${ }^{\mathrm{b}}$, \\ María Patricia Benavides ${ }^{\mathrm{b}, *}$ \\ ${ }^{a}$ Instituto de Química y Fisicoquímica Biológicas Dr Alejandro Paladini (IQUIFIB), Consejo Nacional de Investigaciones Científicas y Técnicas (CONICET), Buenos Aires, \\ Argentina \\ ${ }^{\mathrm{b}}$ Universidad de Buenos Aires, Consejo Nacional de Investigaciones Científicas y Técnicas, Instituto de Química y Fisicoquímica Biológicas Dr Alejandro Paladini \\ (IQUIFIB), Facultad de Farmacia y Bioquímica, Buenos Aires, Argentina \\ ${ }^{\mathrm{c}}$ Universidad de Universidad de Buenos Aires, Facultad de Farmacia y Bioquímica, Departamento de Química Biológica, Buenos Aires, Argentina
}

\section{A R T I C L E I N F O}

\section{Keywords:}

Arabidopsis

Cadmium

Nitrate reductase

Nitrogen

Uptake

NIA genes

\begin{abstract}
A B S T R A C T
The purpose of the present work was to study the effect of the nitrogen source $\left(\mathrm{NO}_{3}{ }^{-} \mathrm{vs} \mathrm{NH}_{4}{ }^{+}\right.$) on cadmium $(\mathrm{Cd})$ uptake, translocation and partition and its associated toxicity in hydroponically-grown Arabidopsis plants. After a short growth period on a complete Hoagland nutrient solution, Arabidopsis seedlings continued in the same growth medium (NA) or were switched to $\mathrm{NO}_{3}{ }^{-}$(N) or $\mathrm{NH}_{4}{ }^{+}$(A) as sole $\mathrm{N}$ sources and supplied with $2.5 \mu \mathrm{M}$ Cd. Unrelated to the nitrogen source, Cd reached higher levels in roots than in leaves. However, when ammonium was the source of nitrogen, Cd accumulation in roots was lower than in $\mathrm{N}$ or NA medium and the metal translocation to the aerial part was restricted, reaching values $25 \%-35 \%$ below the levels observed in plants grown with N or NA. Cadmium negatively affected chlorophyll content and PSII quantum yield, independently of the nitrogen source, with the highest decrease (35\%) under NA treatment. Proline content increased, either with $\mathrm{NA}, \mathrm{N}$ or A supplied in the presence of $\mathrm{Cd}$, whereas a rise in total anthocyanin content was clearly favored when ammonium was the source of nitrogen, with or without Cd. In leaves, while NIA1 and NIA2 expression was markedly reduced by $\mathrm{Cd}$ in the presence of $\mathrm{N}$ or NA, ammonium source slightly reduced NIA1 expression but greatly upregulated NIA2 expression upon Cd exposure. The decay in NR activity was independent of the nitrogen source when $\mathrm{Cd}$ was applied and this decay was accompanied by a great increase in $\mathrm{NH}_{4}{ }^{+}$levels either with nitrates or ammonium in the medium in the presence of Cd. Only NIA1 was detected in roots and its expression, together with NR activity and nitrates levels, was the highest in N medium devoid of Cd. The possibility of reducing $\mathrm{Cd}$ health risks through nitrogen fertilization practices is discussed.
\end{abstract}

\section{Introduction}

Due to industrial activities, fertilizers application, heating systems, urban traffic, and mining, cadmium (Cd) became a major threat to the health of humans and animals that consume plants grown on sites contaminated with this metal. Given the high solubility of Cd in water, this metal can easily enter the food chain through edible plants (Gallego et al., 2012; Lux et al., 2011; Uraguchi and Fujiwara, 2013). Cd has been shown to be a potential prostate carcinogen (Benbrahim-Tallaa et al., 2007). Effective ways to reduce Cd accumulation in crops in order to reduce the entrance of the metal into the food chain are therefore needed.

As nitrogen is an essential nutrient, nitrogen fertilization is a standard practice in many regions, particularly under agronomic settings in which selected, high-productive genotypes are used (Salt et al., 1998). The form of $\mathrm{N}$ applied to the soil is known to influence the availability of trace metals, as well as their uptake and accumulation in plants (Alpha et al., 2009). Therefore, this practice can also potentially increase $\mathrm{Cd}$ accumulation in plants. On the other side, Cd can affect $\mathrm{N}$ metabolism in a direct or indirect way (Hassan et al., 2005). It has been found that $\mathrm{Cd}$ accumulation in plants increased with $\mathrm{N}$ fertilization, and this effect depended on the $\mathrm{N}$ source and the application rate (Maier et al., 2002; Wångstrand et al., 2007). Plants can use both inorganic and organic forms of $\mathrm{N}$ present in soils; however, nitrate $\left(\mathrm{NO}_{3}{ }^{-}\right)$and ammonium $\left(\mathrm{NH}_{4}{ }^{+}\right)$comprise up to $80 \%$ of the total ion uptake for most crops (Marschner and Marschner, 2012).

The disturbances in the plant uptake and distribution of micro- and macronutrients are considered key factors related to Cd toxicity

\footnotetext{
* Corresponding author. Facultad de Farmacia y Bioquímica, Universidad de Buenos Aires, Junín 956, Buenos Aires, 1113, Argentina.

E-mail address: mbenavi@ffyb.uba.ar (M.P. Benavides).

${ }^{1}$ Analía Vazquez and Laura Recalde contribute equally to the present manuscript.
} 
(Gussarson et al., 1996). In this sense, nitrate transporters assume a central role. Li et al. (2010) reported the functional characterization of AtNRT1.8, a member of the NRT1 nitrate-transporters family in Arabidopsis that participates, together with AtNRT1.5, in xylem nitrate transport. Several reports suggest that AtNRT1.8 mediates $\mathrm{Cd}^{2+}$ tolerance in Arabidopsis because it restricts nitrate translocation to shoots in response to $\mathrm{Cd}^{2+}$ addition (Goyon and Gaymard, 2010).

It has been reported that $\mathrm{Cd}$ can enter the plant through transporters commonly used for micronutrient uptake (Clemens, 2006; Roth et al., 2006), eventually leading to the deficiency of essential micronutrients like Fe or Zn (Nazar et al., 2012). Divalent cations such as $\mathrm{Mg}^{2+}, \mathrm{Zn}^{2+}$, and $\mathrm{Mn}^{2+}$ may compete with $\mathrm{Cd}^{2+}$ to enter the roots (Ramachandran and D'Souza, 2002; Tlustoš et al., 2006). Therefore, the concentration of these micronutrients in the rhizosphere could affect Cd uptake. On the other hand, the chemical form of $\mathrm{N}$ supplied to the plants can affect their ion uptake balance, showing $\mathrm{NO}_{3}{ }^{-}$-fed plants more accumulation of cations (including $\mathrm{Cd}$ ) than $\mathrm{NH}_{4}{ }^{+}$-fed ones due to the antagonistic effects between $\mathrm{NH}_{4}{ }^{+}$and $\mathrm{Cd}^{2+}$ (Hu et al., 2013; Xie et al., 2009).

Several studies strongly suggest that the iron transporter IRT1 is mainly responsible for $\mathrm{Cd}^{2+}$ influx into root cells (Clemens, 2006; Lux et al., 2011). On the other hand, higher expression of the iron transporter gene IRT1 was observed in $\mathrm{NO}_{3}{ }^{-}$-fed plants than in $\mathrm{NH}_{4}{ }^{+}$-fed plants in tomato (Luo et al., 2012). This fact, together with the reported involvement of $\mathrm{NO}_{3}{ }^{-}$in regulating IRT1 (Jeong and Guerinot, 2009), led us to suppose that $\mathrm{NO}_{3}{ }^{-}$availability may influence $\mathrm{Cd}$ accumulation in plants.

Nitrogen also plays a key role in detoxifying plants from heavy metals via glutamate and GSH in the presence of Cd. When glutamate is limited, competitive inhibition results with reductions in the biosynthesis of chlorophyll, proteins and nucleic acid, because the GSH synthesis consumes more glutamate under Cd stress (Zhang et al., 2014a)

Recently, it has been proposed that plants may benefit from the simultaneous application of nitrate $\left(\mathrm{NO}_{3}{ }^{-}\right)$and ammonium $\left(\mathrm{NH}_{4}{ }^{+}\right)$, which can influence the bioaccumulation of heavy metals (de Sousa Leite and Monteiro, 2019). Although many authors have studied the effect of nitrate versus ammonium nutrition, results might be controversial depending on the species, $\mathrm{NO}_{3}{ }^{-}$or $\mathrm{NH}_{4}{ }^{+}$concentrations used, organ of interest and plant age (Cheng et al., 2016; Luo et al., 2012; Sarwar et al., 2010; Xie et al., 2009). The present study was designed to examine whether the form of $\mathrm{N}$ supply alters $\mathrm{Cd}$ uptake and distribution in root and shoot tissues in the model plant Arabidopsis thaliana and to relate this pattern with the toxic behavior of this heavy metal inside the plant Different growth, genetic, and biochemical markers related to $\mathrm{N}$ source of nutrition and abiotic stress response were measured for this purpose.

\section{Materials and methods}

\subsection{Plant material and growth conditions}

Seeds of Arabidopsis thaliana (L.) Heynh (Columbia ecotype) were sown in commercial soil (Klasmann Deilmann GMBH TS-1), and after 20 days, plants were transferred to a hydroponic system supplied with a complete nutrient solution for 7 days. Plants were grown in a controlled environment $\left(22{ }^{\circ} \mathrm{C}\right.$, 10-h-light/14-h-dark, $70 \%$ relative humidity, $120 \mu \mathrm{mol} \mathrm{m} \mathrm{m}^{-2} \mathrm{~s}^{-1}$ light intensity). After this adaptation period, plants continued growing under the following scheme:

- Combined nitrogen source (nitrate + ammonium, NA, or nitrate + ammonium + Cd, NA-Cd): $0.5 \mathrm{mM} \mathrm{KNO}_{3}, 0.25 \mathrm{mM}$ $\left(\mathrm{NH}_{4}\right)_{2} \mathrm{SO}_{4}, 0.315 \mathrm{mM} \mathrm{K}_{2} \mathrm{SO}_{4}, 0.37 \mathrm{mM} \mathrm{NaH}_{2} \mathrm{PO}_{4}, 0.25 \mathrm{mM} \mathrm{MgSO}_{4}$, $2.5 \mathrm{mM}$ Fe-EDTA, micronutrient solution, pH 5.5.

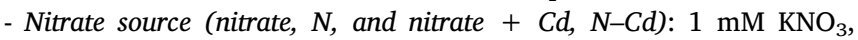
$0.062 \mathrm{mM} \mathrm{K}_{2} \mathrm{SO}_{4}, 0.37 \mathrm{mM} \mathrm{NaH}_{2} \mathrm{PO}_{4}, 0.25 \mathrm{mM} \mathrm{MgSO}_{4}, 2.5 \mathrm{mM} \mathrm{Fe}-$ EDTA, micronutrient solution, $\mathrm{pH} 5.5$.
- Ammonium source (ammonium, A, and ammonium + Cd, A-Cd): $0.5 \mathrm{mM}\left(\mathrm{NH}_{4}\right)_{2} \mathrm{SO}_{4}, 0.62 \mathrm{mM} \mathrm{K}_{2} \mathrm{SO}_{4}, 0.37 \mathrm{mM} \mathrm{NaH}_{2} \mathrm{PO}_{4}, 0.25 \mathrm{mM}$ $\mathrm{MgSO}_{4}, 2.5 \mathrm{mM}$ Fe-EDTA, micronutrient solution, $\mathrm{pH}$ 5.5.

The nutrient solutions were renewed every 2 days. Plants were harvested after 7 days of treatment when several phenotypic and biochemical determinations were performed. Additionally, samples were frozen in liquid nitrogen and stored at $-80{ }^{\circ} \mathrm{C}$ for further biochemical assays and RNA extraction.

Treatments: NA (control), NA + Cd; N; N + Cd; A; A + Cd

\subsection{Analysis of growth parameters}

The shoot fresh biomass and relative shoot dry biomass (as a percentage) were determined: Shoots were weighed and then dried at $70{ }^{\circ} \mathrm{C}$ until constant weight.

Root length and rosette size: root length was measured using a rule, and rosette size was calculated based on the longest diameter.

\subsection{Chlorophyll content}

Leaf tissue ( $0.2 \mathrm{~g}$ per sample) was extracted in $1.5 \mathrm{ml}$ 96\% ethanol, boiled, and chlorophyll was quantified according to Wintermans and De Mots (1965). Minimal and maximal chlorophyll fluorescence (Fo and $\mathrm{Fm})$, variable chlorophyll fluorescence $(\mathrm{Fv}=\mathrm{Fm}$ - Fo), and maximum photochemical quantum yield of photosystem II (Fv/Fm ratio) were measured on an area of $0.5 \mathrm{~cm}^{2}$ of the leaf surface using a pulse amplitude-modulated fluorometer FMS2 (Hansatech, King's Lynn, U.K). Measurements were taken after reaching a steady-state value of basal fluorescence. The effective quantum yield of photosystem II was measured by the saturating pulse method.

\subsection{Cadmium and iron content in leaves and roots}

Leaves and roots samples were dried at $70{ }^{\circ} \mathrm{C}$, dissolved in concentrated $\mathrm{HNO}_{3} / \mathrm{HCl}$ at $120^{\circ} \mathrm{C}$, and then digested with $\mathrm{HClO}_{4}$ at $180^{\circ} \mathrm{C}$. The concentrations of cadmium and iron in the samples were analyzed using inductively coupled plasma mass spectrometry (ICPMS) (PerkinElmer - Sciex, Model: ELAN DRC-e) at the mass spectroscopy facility in the Instituto de Química de San Luis, Universidad de San Luis. The total amount of both elements was expressed as $\mu \mathrm{g} . \mathrm{g}^{-1} \mathrm{DW}$. To estimate the transfer of cadmium from roots to leaves, the translocation factor (TF) was calculated according to Marchiol et al. (2004), with the following equation:

$\mathrm{TF}=\mathrm{C}$ leaves $/ \mathrm{C}$ root, where $\mathrm{C}=\mathrm{Cd}$ in $\mathrm{mg} \mathrm{g}^{-1}$ dry weight

\subsection{Proline content}

Rosette leaves (100 mg per sample) were ground in liquid $\mathrm{N}$ and homogenized in $2 \mathrm{ml}$ of $5 \%$ aqueous sulfosalicylic acid. Proline content was determined by reaction with ninhydrin-acid reactive, according to Bates et al. (1973). As Cd-treated samples presented a violet-pink coloration, color-blanks were prepared.

\subsection{Thiobarbituric acid reactive substances (TBARS)}

Lipid peroxidation in leaves was measured according to the method of Heath and Packer (1968) by estimating thiobarbituric acid reactive substances (TBARS). TBARS content was calculated using the extinction coefficient $\left(155 \mathrm{mM}^{-1} \mathrm{~cm}^{-1}\right)$.

\subsection{Guaiacol peroxidase activity}

Fresh leaves samples (100 mg) were ground in liquid nitrogen and stored at $-80{ }^{\circ} \mathrm{C}$. Extracts were made with $1 \mathrm{ml}$ extraction buffer (50 mM potassium phosphate buffer, $\mathrm{pH}$ 7.8, $1 \mathrm{mM}$ EDTA, and PVPP). 
Guaiacol peroxidase (GPOX; EC 1.11.1.7) activity was measured in a reaction mixture containing $50 \mathrm{mM}$ potassium phosphate buffer $\mathrm{pH}$, $10 \mathrm{mM} \mathrm{H}_{2} \mathrm{O}_{2}, 10 \mathrm{mM}$ guaiacol, and the enzyme extract according to the method of Maehly and Chance (1954). The formation of tetraguaiacol was detected at $470 \mathrm{~nm}$ in a Flex Station 3 microplate reader, and peroxidase activity was calculated by using the extinction coefficient of $26.6 \mathrm{M}^{-1} \mathrm{~cm}^{-1}$. Results were analyzed with SoftMax ${ }^{\circledast}$ Pro software.

\subsection{Total monomeric anthocyanin content}

The determination of total monomeric anthocyanin content was based on the structural change of the anthocyanin chromophore between $\mathrm{pH} 1.0$ and 4.5. Anthocyanin pigment concentration was expressed as cyanidin-3-glucoside equivalents, according to the method described by Lee et al. (2005).

\subsection{RNA extraction and cDNA preparation}

Plant material (100 mg of leaves or roots) was ground in liquid $\mathrm{N}$ and stored at $-80{ }^{\circ} \mathrm{C}$ until RNA extraction. The extraction was made using TRIZOL Reagent (Invitrogen) according to the manufacturer's protocol. The quality of RNA and the presence of DNA were tested by using agarose gel electrophoresis. Only non-degraded RNA was used for subsequent DNase digestion treatments (Thermo Fisher Scientific) to obtain pure RNA. Then, the total RNA amount was quantified spectrophotometrically (Thermo Scientific NanoDrop ${ }^{\mathrm{TM}}$ ) at $260 \mathrm{~nm}$. Two micrograms of total RNA were used to synthesize cDNA by reverse transcriptase enzyme (Thermo Fisher Scientific) following the manufacturer's protocol. The cDNA samples were used as templates to quantify nitrate reductase genes (NIA 1 and NIA 2) expression in leaves and roots, as well as $\mathrm{F} 3 \mathrm{H}$ expression in leaves.

\subsection{Estimation of transcript level by $q R T-P C R$}

mRNA levels were detected using the SYBR Green RT-PCR kit (FastStart Universal SYBR Green Master Roche), with the following pairs of gene primers:

NIA 1: fw 5'ATCGTCAAAGAAACCGAAGTC 3'; rev 5'GAGGAGTCG TCGTAACTGTC $3^{\prime}$

NIA 2: fw 5'CTGACTCTTCCTCGCCTAAC 3', rev 5'TCCAATGGGAG CCAACAG $3^{\prime}$

F3H: fw 5'ACTGACCCTGGAACCATTAC 3', rev 5'ACGACAAACGCT CCTTCAAC $3^{\prime}$

The RT-PCR analysis was performed with Applied Biosystems ${ }^{\circledast}$ StepOnePlus ${ }^{\mathrm{TM}}$ with the following cycling conditions: 2 min at $50{ }^{\circ} \mathrm{C}$, 10 min at $95^{\circ} \mathrm{C}, 15 \mathrm{~s}$ at $95^{\circ} \mathrm{C}, 1 \mathrm{~s}$ at $50^{\circ} \mathrm{C}, 35$ cycles, and the AtUBQ10 housekeeping gene, used as control in the PCR, was amplified using the following pair of primers: 5'TTGCGTCTGCGTGGAGGTATG-3' and 5' ATCCGCCAAAGTACGACCATCC-3'

Each cDNA sample was run in triplicate. The amplification of PCR products was registered by the intercalation of SYBR-Green.

\subsection{Nitrate reductase (NR) activity}

Fresh leaves or roots ( $100 \mathrm{mg}$ per sample) were excised from plants and homogenized with $0.5 \mathrm{ml}$ of $0.25 \mathrm{mM}$ HEPES-KOH buffer solution (pH 7.5) containing $3 \%(\mathrm{w} / \mathrm{v})$ polyvinylpolypyrrolidone (PVPP), $1 \mathrm{mM}$ EDTA, and $7 \mathrm{mM}$ cysteine. The homogenate was centrifuged at 17,000 $\mathrm{g}$ for $15 \mathrm{~min}$, and the supernatant was used for NR (E.C.1.7.1.1) activity determination, in a reaction mixture containing $25 \mathrm{mM}$ HEPES-KOH buffer (pH 7.5), $100 \mathrm{mM} \mathrm{NADH,} 5 \mathrm{mM} \mathrm{KNO}_{3}$, and $0.1 \mathrm{ml}$ of the plant extract, according to Yaneva et al. (2002) and Savidov et al. (1997). To obtain a negative control, $0.2 \mathrm{ml}$ of $0.25 \mathrm{mM}$ HEPES-KOH was added without the addition of NADH. After $30 \mathrm{~min}$ of incubation at $30{ }^{\circ} \mathrm{C}$, the reaction was stopped by the addition of $50 \mu \mathrm{l}$ of zinc acetate. Nitrite content was determined by reaction with sulfanilamide $\left(0.01 \mathrm{~g} \mathrm{ml}^{-1}\right.$
$1.5 \mathrm{~N} \mathrm{HCl}$ ) and $0.8 \mathrm{mM} \mathrm{N}$-(1-naphthyl)-ethylene-diamine dihydrochloride. The absorbance was measured at $540 \mathrm{~nm}$. For nitrite calculation, a standard curve of $\mathrm{NaNO}_{2}$ was used. Nitrite concentration was expressed as nmol $\mathrm{NO}_{2} \mathrm{Na} \mathrm{min}^{-1} \mathrm{mg}^{-1} \mathrm{FW}$. As Cd-treated samples presented a violet-pink coloration, color-blanks were prepared.

\subsection{Nitrate and ammonium content}

Arabidopsis leaves and roots were dried at $85{ }^{\circ} \mathrm{C}$ until constant weight. Dried material $(25 \mathrm{mg})$ was ground to powder and incubated in $10 \mathrm{ml}$ of distilled water for $2.5 \mathrm{~h}$. Nitrates were measured using the method described by Cataldo et al. (1975) after a reaction with salicylic acid. Ammonium content was measured according to Hachiya et al. (2012).

\subsection{Statistical analysis}

Results are reported as means \pm SD of at least two independent experiments with three or four replicates. The assays were carried out with a factorial design with two levels for cadmium (factor 1) and three for nitrogen sources (factor 2). The analysis of variance was performed with a two-factor ANOVA using the statistical software Infostat. Differences were compared by Tukey's multiple range test.

\section{Results}

\subsection{Effect of cadmium and nitrogen source on Arabidopsis growth}

Cd treatment significantly reduced the shoot fresh biomass and increased the relative shoot dry biomass in NA- and N-fed plants (Table 1). In A-fed plants, growth was per se reduced, and changes upon Cd treatment were not significant. In addition, plants grown with $\mathrm{NH}_{4}{ }^{+}$ as the sole nitrogen source showed $17 \%$ shorter roots than those grown under NA or $\mathrm{N}$ treatments in the absence of the metal. Cd addition caused a significant inhibition of root length, independently of the nitrogen source included (Table 1, Fig. 1); this inhibition was less evident, but still significant, when ammonium was the sole nitrogen source. The size of the rosette, which was similar under different $\mathrm{N}$ sources, was negatively affected by Cd treatment in all cases (Table 1).

\subsection{Effect of nitrogen source on cadmium and iron accumulation in root and leaves}

The form of $\mathrm{N}$ present in the nutrient solution significantly affected Cd levels in A. thaliana leaves and roots. As can be seen in Fig. 2A, plants cultivated in a solution containing $\mathrm{NH}_{4}{ }^{+}$as the only nitrogen source contained in their leaves significantly less Cd (35\%) than plants grown with both $\mathrm{N}$ sources (NA) or with $\mathrm{N}$ alone, in agreement with a lower translocation factor (TF) as compared to the other treatments.

\section{Table 1}

Growth and photosynthesis parameters measured in Arabidopsis plants grown in different nitrogen sources, with or without Cd.

\begin{tabular}{|c|c|c|c|c|c|c|}
\hline & $\begin{array}{l}\text { Fresh } \\
\text { Biomass } \\
\text { (mg) }\end{array}$ & $\begin{array}{l}\text { Shoot Dry } \\
\text { Biomass } \\
(\%)\end{array}$ & $\begin{array}{l}\text { Root } \\
\text { lenght } \\
(\mathrm{cm})\end{array}$ & $\begin{array}{l}\text { Rosette } \\
\text { Size } \\
(\mathrm{cm})\end{array}$ & $\begin{array}{l}\text { Chlorophyll } \\
\text { A + B ( } \mu g^{-1} \\
\text { FW) }\end{array}$ & $\begin{array}{l}\text { F PSII } \\
(\mu \mathrm{mol} \\
\mathrm{m}^{-2} \\
\left.\mathrm{~s}^{-1}\right)\end{array}$ \\
\hline NA & $42.70 \mathrm{a}$ & $7,44 \mathrm{c}$ & $7,28 \mathrm{a}$ & 3,71 a & $1330,21 \mathrm{a}$ & $0,49 \mathrm{a}$ \\
\hline NA-Cd & $30.07 \mathrm{~b}$ & $9,56 \mathrm{ab}$ & $4,08 \mathrm{c}$ & $2,44 \mathrm{~b}$ & $862,32 \mathrm{~d}$ & $0,39 \mathrm{c}$ \\
\hline $\mathrm{N}$ & $48.30 \mathrm{a}$ & $8,72 \mathrm{~b}$ & $7,46 \mathrm{a}$ & $3,75 \mathrm{a}$ & 1091,49 bc & $0,47 \mathrm{ab}$ \\
\hline $\mathrm{N}-\mathrm{Cd}$ & $31.50 \mathrm{~b}$ & $10,23 \mathrm{a}$ & $4,29 \mathrm{c}$ & $2,92 \mathrm{~b}$ & $826,6 \mathrm{~d}$ & $0,40 \mathrm{bc}$ \\
\hline A & $38.45 \mathrm{ab}$ & $10,09 \mathrm{a}$ & $6,06 \mathrm{~b}$ & $3,39 \mathrm{a}$ & $1160,48 \mathrm{ab}$ & $0,54 \mathrm{a}$ \\
\hline A-Cd & $24.05 \mathrm{~b}$ & $9,46 \mathrm{ab}$ & $4,46 \mathrm{c}$ & $2,6 \mathrm{~b}$ & $930,85 \mathrm{~cd}$ & $0,28 \mathrm{~d}$ \\
\hline
\end{tabular}

The values are the average \pm SE of three independent experiments with five replicates each treatment. The different letters within the rows indicate significant differences respect to NA ( $p<0.05$ ) according to the Tukey test. 

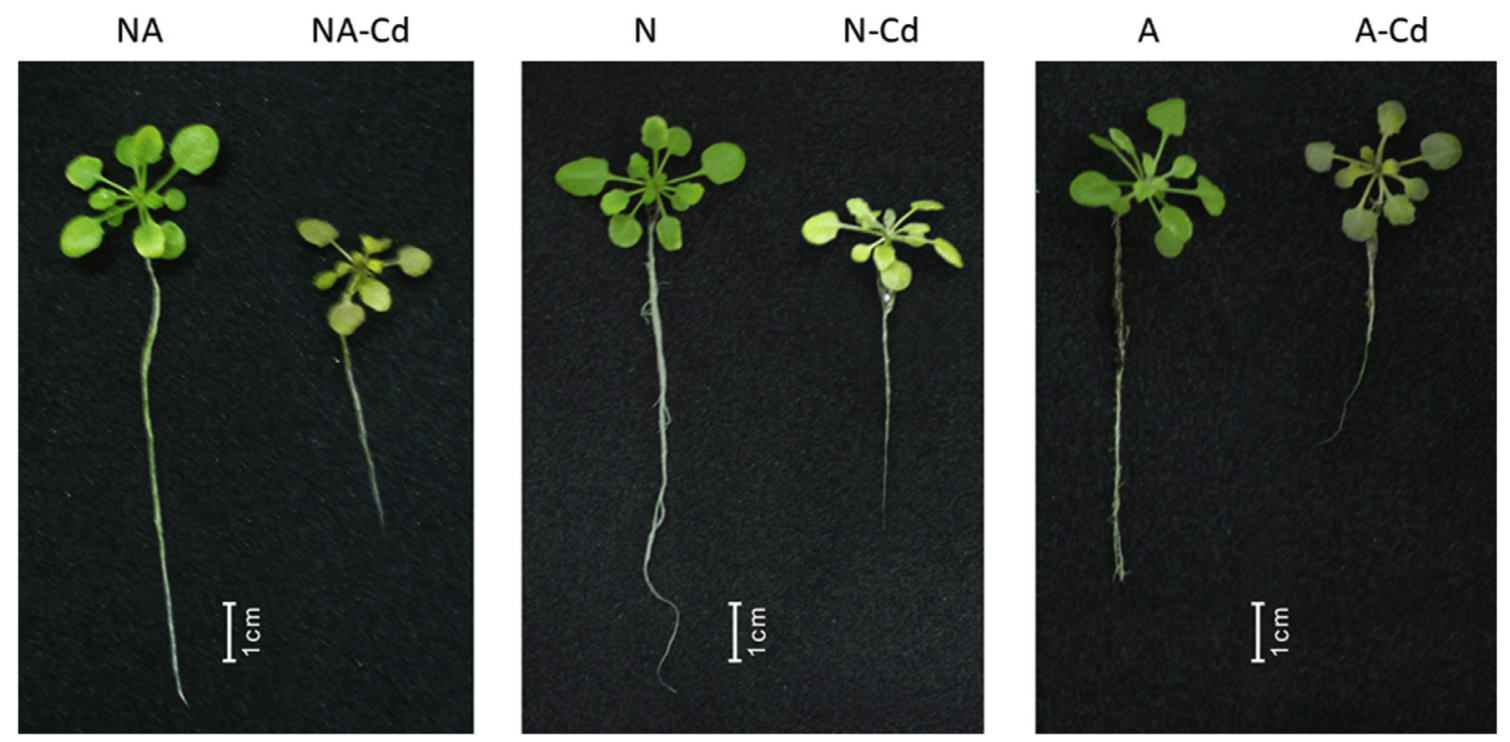

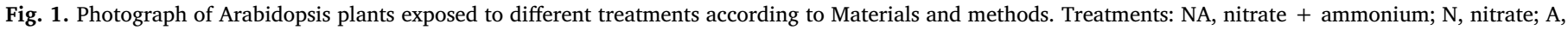
ammonium; NA-Cd, N-Cd, and A-Cd correspond to the same treatments with the addition of $2,5 \mu \mathrm{M} \mathrm{CdCl}_{2}$.

The TF was maximum for $\mathrm{N}$-fed plants (0.58). Regardless of the nitrogen source, Cd reached higher levels in roots than in leaves.

The iron content was also higher in leaves than in roots, with no significant variations among treatments (Fig. 2B).

\subsection{Cadmium toxicity under different nitrogen sources}

In order to evaluate $\mathrm{Cd}$ toxicity, different biochemical markers of $\mathrm{Cd}$ toxicity were measured; these are depicted in Table 1 and Fig. 3. Both the nitrogen source and the presence of the metal affected chlorophyll content in Arabidopsis (Table 1). The concentration of this essential pigment significantly diminished in plants developed in $\mathrm{N}$ medium compared to NA medium. Cadmium addition also caused reductions in chlorophyll contents in all cases; the highest decrease (35\%) was observed in plants fed with the complete nutrient medium (NA). In agreement with the decrease in chlorophyll content, the PSII quantum yield also decayed significantly in Cd-treated plants (Table 1).

Proline content significantly increased in the leaves of Cd-treated plants (Fig. 3A). A 6-fold rise was observed in $\mathrm{N}+$ Cd-treated plants as compared to untreated plants, followed by a 3-fold increase in $\mathrm{NA}+\mathrm{Cd}$ and a 2.5-fold increase in A + Cd (Fig. 3A).

Cd addition significantly increased GPOX activity (Fig. 3B): 73\% in $\mathrm{N}-\mathrm{Cd}, 107 \%$ in NA-Cd, and $120 \%$ in A-Cd treatments. The nitrogen source by itself did not alter this enzyme activity. The expression of ferulate-3-hydroxylase gene, $\mathrm{F3H}$, selected to detect any alteration in the phenolic metabolism, was notoriously increased under cadmium treatments, irrespective of the nitrogen source (Fig. 3C). However, total anthocyanins content expressed as cyanidin-3-glucoside equivalents
A

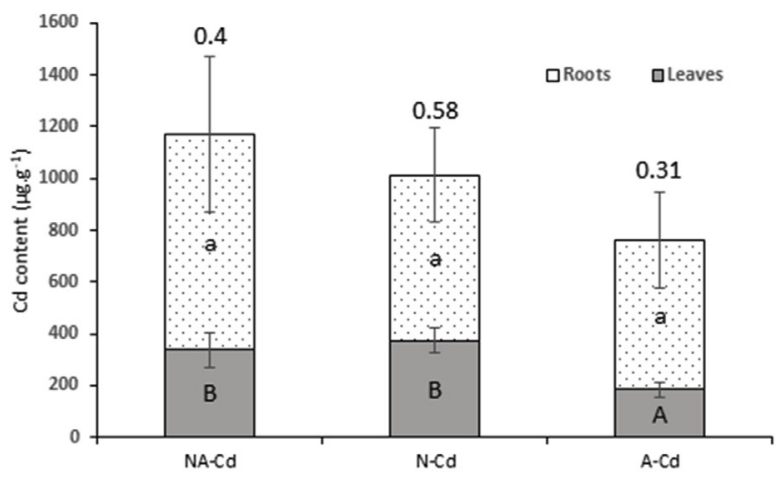

Fig. 2. Cadmium (A) and iron (B) contents in roots and leaves of Arabidopsis plants exposed to different treatments according to Materials and methods. Treatments: NA, nitrate + ammonium; N, nitrate; $\mathrm{A}$, ammonium; NA-Cd, N-Cd, and A-Cd correspond to the same treatments with the addition of $2,5 \mu \mathrm{M} \mathrm{CdCl}_{2}$. Values are the mean from two independent experiments with three replicated measurements. To indicate statistical differences, capital letters are used for leaves and lower-case letters for roots. Translocation factor (TF) was calculated as described in Material and methods.

B

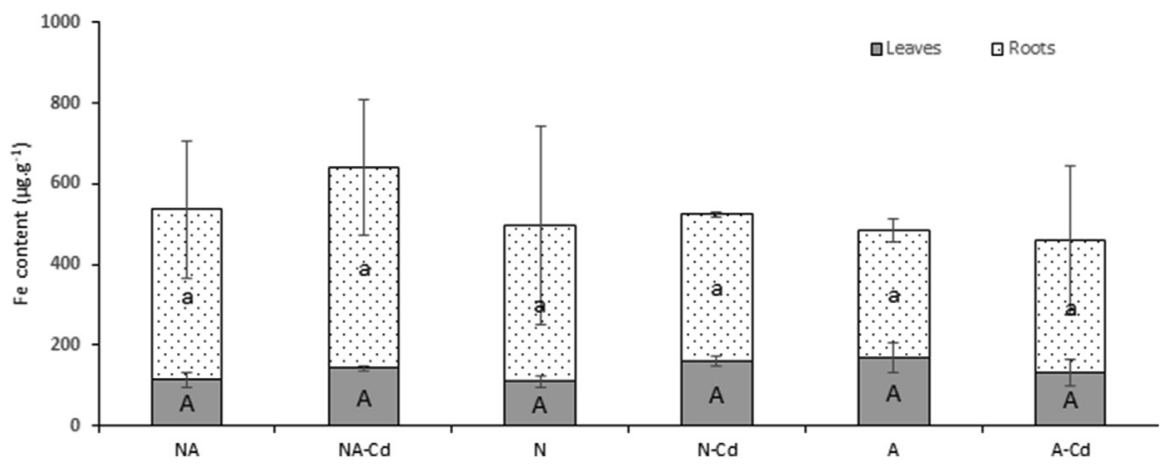



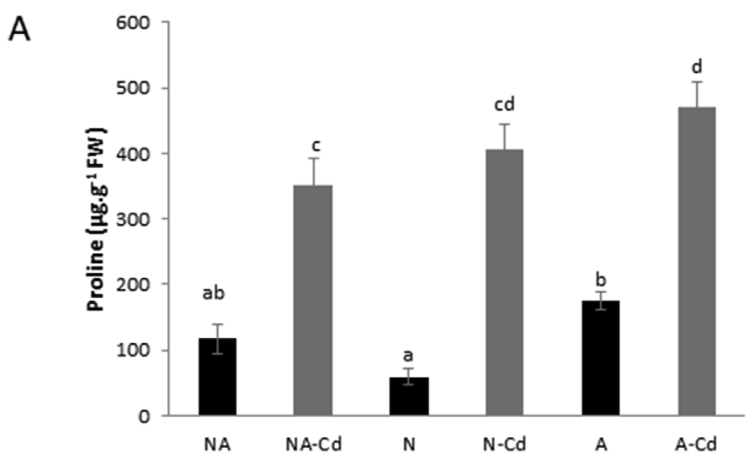

C

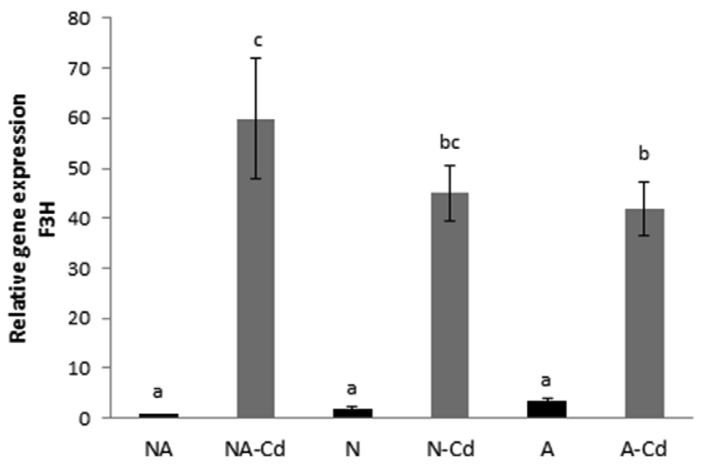

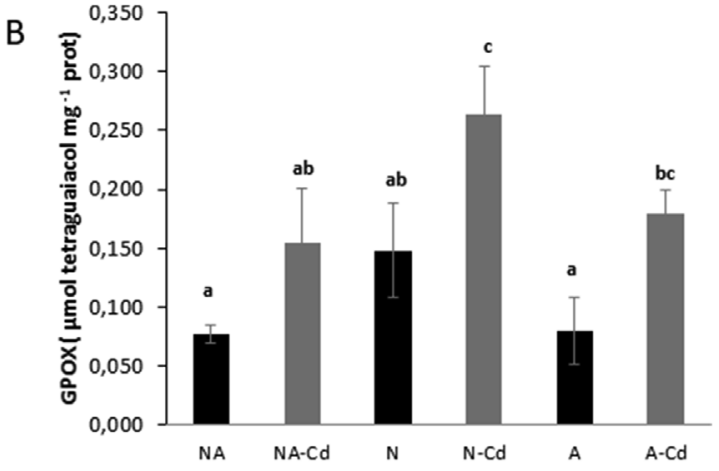

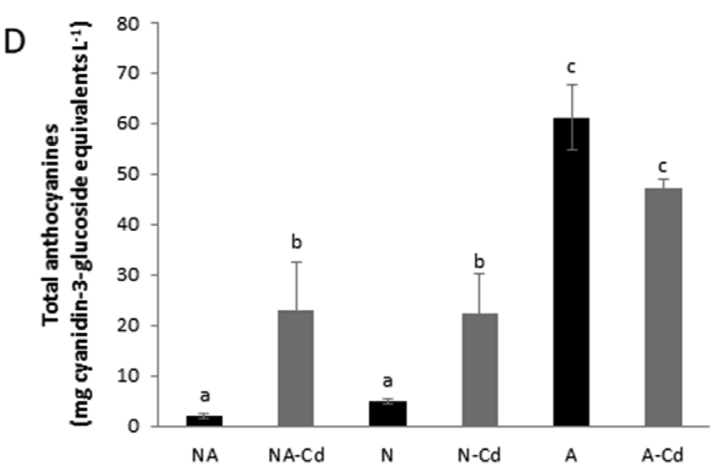

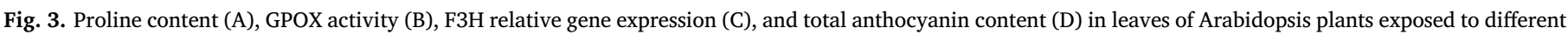

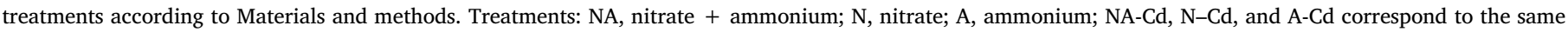

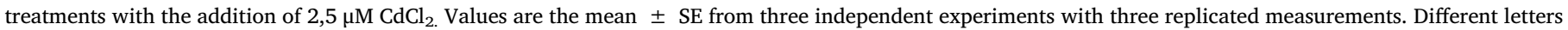
indicate significant differences with respect to NA treatment $(p<0.05)$ according to the Tukey test.

increased in variable extents, depending on the $\mathrm{N}$ source. The presence of $\mathrm{NH}_{4}{ }^{+}$itself caused a striking rise in total anthocyanin content $(330 \%$ over the NA control). In this treatment, Cd incorporation did not result in significant change (Fig. 3D)

3.4. Cadmium effect on nitrate reductase gene expression, enzyme activity, and nitrate and ammonium contents

The presence of $\mathrm{Cd}$ in the growth medium caused a significant inhibition in the expression of NIA1 and NIA2 genes in Arabidopsis leaves when nitrate was present in the nutrient solution, as unique $\mathrm{N}$ source or combined with ammonium (Fig. 4A). Besides, both genes were downregulated in the A treatment. However, Cd addition reverted this response, particularly in the case of NIA1, which demonstrated the highest expression level under A + Cd. In accordance with this decreased gene expression, NR activity was significantly reduced in $\mathrm{N}+\mathrm{Cd}$ and NA + Cd-treated plants (Fig. 4B), and, as expected, also in A-fed plants, due to the lack of available substrate. Despite the increased NIA expression, NR activity was also reduced in A + Cd plants. Cadmium also significantly reduced nitrate contents in $\mathrm{N}$ and NA treatments, whereas nitrate level was comparable to that observed without metal in A-fed plants. On the other hand, Cd addition to the nutrient solution increased ammonium contents, being this effect more pronounced in $\mathrm{N}$-fed plants (Fig. 4D).

In roots, NIA1 expression was particularly high in N-fed plants, and $\mathrm{Cd}$ addition resulted in significant reductions of NIA1 transcripts, NR activity, and nitrate concentration in N-and NA-fed plants (Fig. 5A, B, 5C), while A-fed plants, with low to negligible levels of all these markers, experienced no significant changes upon Cd addition. Conversely, ammonium content, which was maximum for A-fed plants, increased in all treatments except in A + Cd (Fig. 5D).

\section{Discussion}

In soils contaminated with cadmium, nitrogen fertilization could improve the efficiency of the metal phytoextraction. Plants can absorb both nitrate and ammonium ions under natural conditions; however, they act differently on the physiological and metabolic processes of plants (Lu et al., 2005). The increased percentage of shoot biomass showed by plants grown on ammonium as sole nitrogen source and Cdtreated plants, compared to those grown in NA nutrient media, suggested that plant water content was lower under the former treatments, in accordance to that found for $\mathrm{NH}_{4}{ }^{+}$-fed plants by Hu et al. (2013). It has been reported that $\mathrm{Cd}$ induce stomatal closure and reduced water loss (Rabêlo et al., 2018). However, de Sousa Leite and Monteiro (2019) showed that plants supplied with $\mathrm{NO}_{3}{ }^{-}$and $\mathrm{NH}_{4}{ }^{+}$at a 50/50 ratio were less prone to $\mathrm{Cd}$-induced stomatal closure and water loss compared to $70 / 30$ ratio, indicating a beneficial effect of the increased $\mathrm{NH}_{4}{ }^{+}$in the medium, because despite plants increase transpiration, simultaneously have to open their stomata in order to obtain $\mathrm{CO}_{2}$ (Taiz et al., 2014) and thus, improve photosynthetic parameters. This could be occurring in ammonium-fed Arabidopsis plants in our experimental conditions.

It is widely known that cadmium inhibits plant growth and development (Gallego et al., 2012), but the information about the effect of different nitrogen sources on cadmium toxicity is still limited.

In rice plants grown under three different $\mathrm{N}$ sources (ammonium sulfate, ammonium nitrate, and calcium nitrate), no significant differences in growth parameters such as plant height and tiller number per plant were detected, but $\mathrm{Ca}(\mathrm{NO} 3)_{2}$-fed plants were the most affected upon Cd addition (Hassan et al., 2005, 2008). It is noteworthy that roots and leaves of Arabidopsis plants fed with $\mathrm{NH}_{4}{ }^{+}$as the sole $\mathrm{N}$ source showed lower $\mathrm{Cd}$ accumulation, but also significantly reduced root length. This decreased uptake and accumulation of Cd in ammonium fed plants was probably due to direct competition between $\mathrm{Cd}^{2+}$ and $\mathrm{NH}_{4}{ }^{+}$, as it has been described for $\mathrm{Ca}^{2+}$ or $\mathrm{Mg}^{2+}$ ions (Rayar and Hai, 1977) or, because the influx of ammonium into the cytoplasm 
A

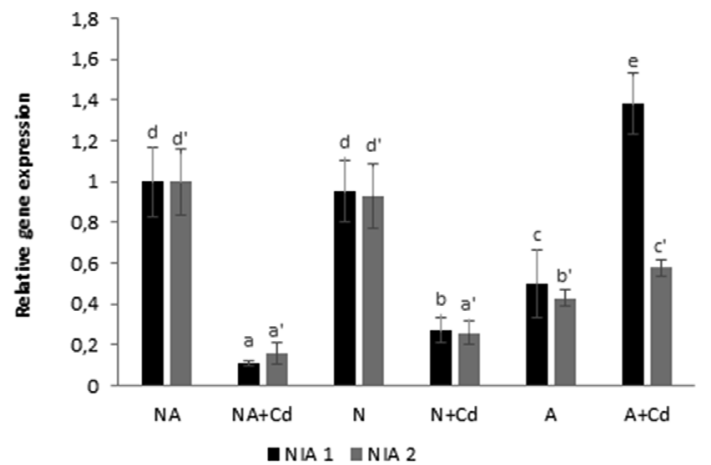

C

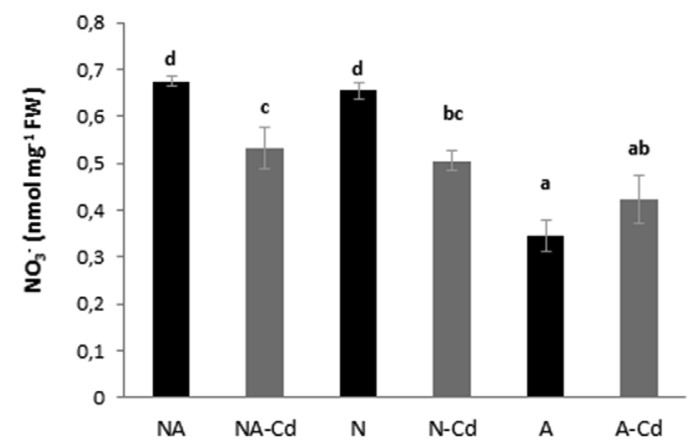

B

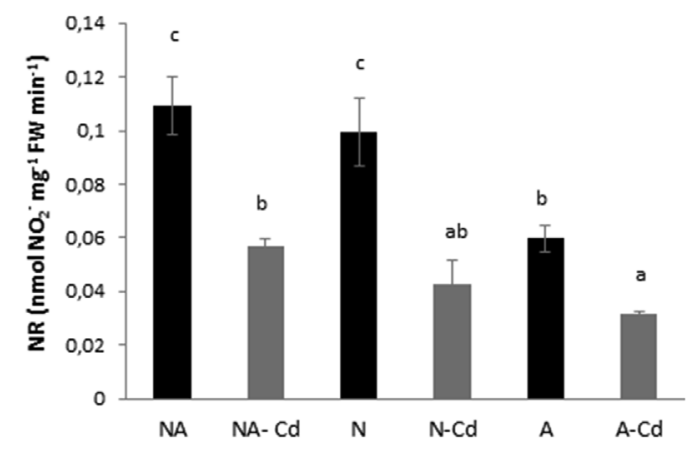

D

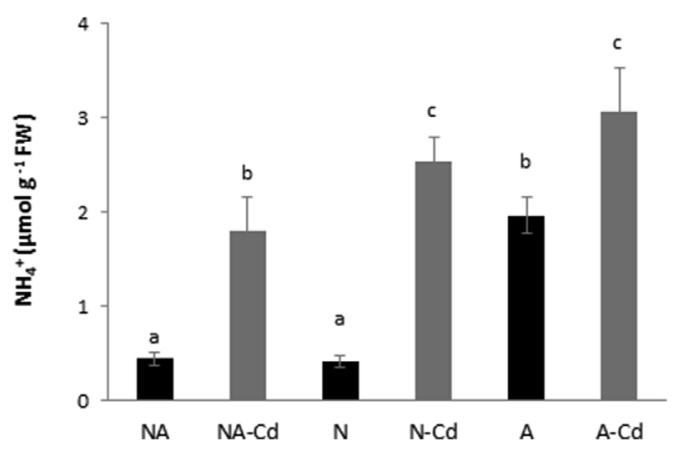

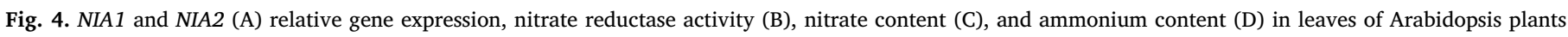

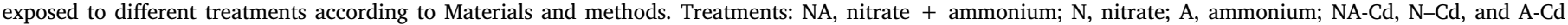

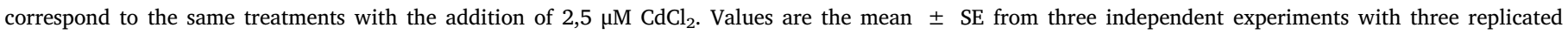
measurements. Different letters indicate significant differences with respect to NA treatment $(p<0.05)$ according to the Tukey test.

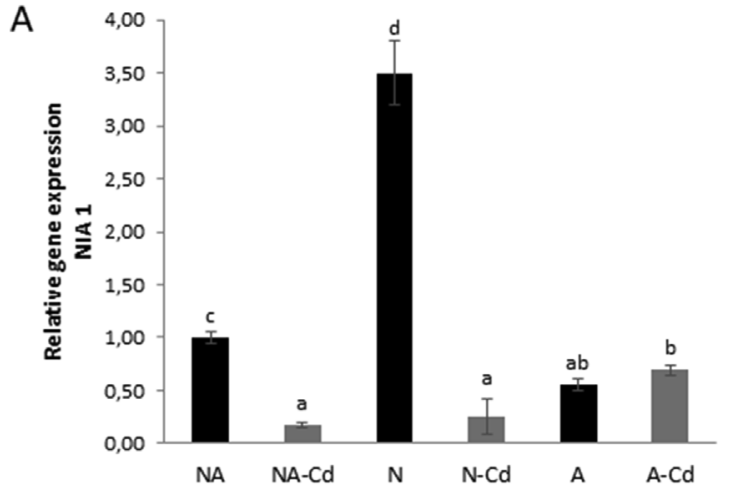

C

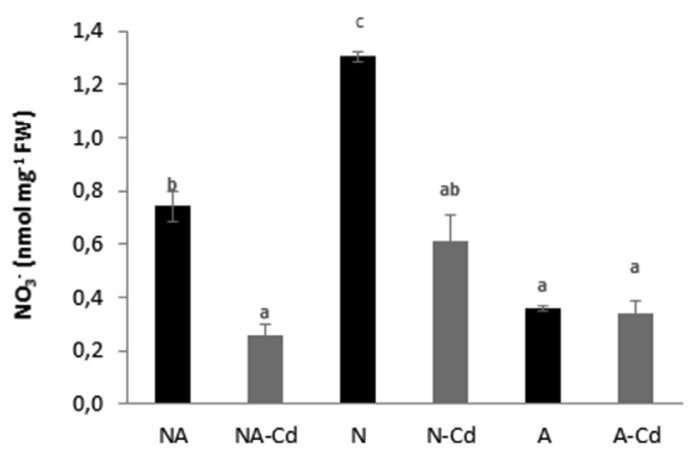

B

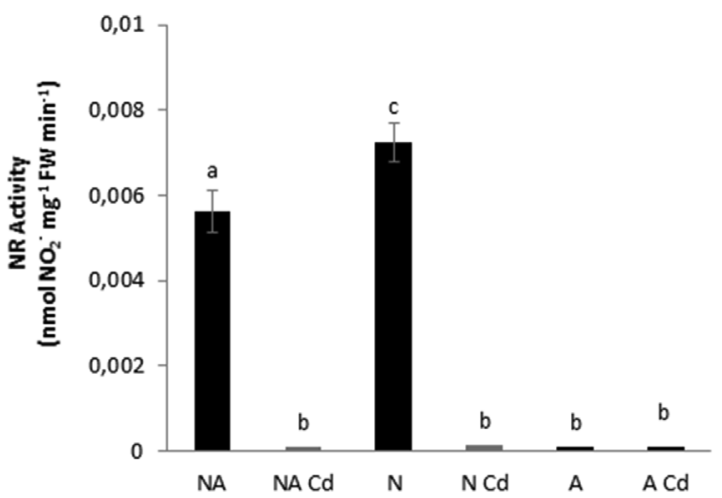

D

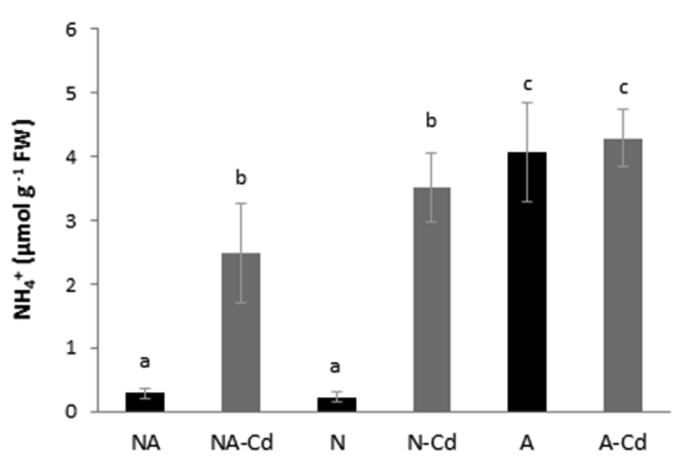

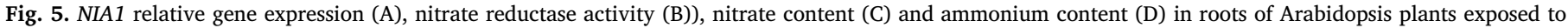

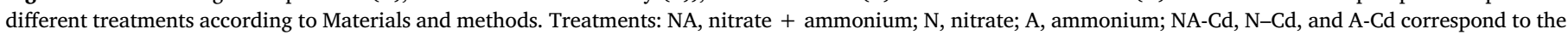

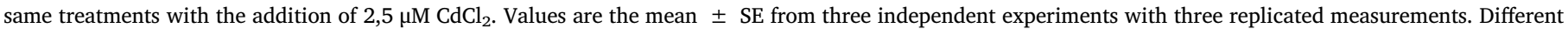
letters indicate significant differences with respect to NA treatment $(p<0.05)$ according to the Tukey test. 
causes a depolarization of the membrane potential, which in turn reduces the uptake of all cations, including Cd (McClure et al., 1998). Nevertheless, other processes which could have affected Cd uptake, partitioning, and translocation from roots to shoots cannot be ruled out (Clemens, 2006).

$\mathrm{Cd}$ accumulation in plants fed with diverse $\mathrm{N}$ sources has been variable (Hassan et al., 2008 and references therein). Although there are contradictory results respect to cadmium accumulation in relation to the nitrogen source, our results are in line with those reported by Nasraoui-Hajaji et al. (2012) in leaves of tomatoes. In a similar way, Thlaspi caerulesscens plants irrigated with $\mathrm{NO}_{3}{ }^{-}$showed higher amounts of cadmium than $\mathrm{NH}_{4}{ }^{+}$-fed plants, independently of the lower $\mathrm{pH}$ found in the rhizosphere of $\mathrm{NH}_{4}{ }^{+}$treated plants (Xie et al., 2009). In Sedum plumbizincicola, higher absorption of cadmium was also observed in plants irrigated with a nitrate-containing solution than in those irrigated with an ammonium-containing solution, probably due to a $\mathrm{NO}_{3}{ }^{-}$-induced expression of cadmium transporters involved in symplastic uptake and transportation in the roots of this plant species ( $\mathrm{Hu}$ et al., 2013), in accordance to what was observed in Arabidopsis plants in the present work. On the contrary, in Solanum nigrum, $\mathrm{NH}_{4}{ }^{+}$increased Cd concentration both in shoot and leaves, as compared to $\mathrm{NO}_{3}{ }^{-}$ irrigated plants. Similar results were documented in Carpobrotus rossii leaves, irrespective of the Cd concentration in the nutrient solution (Cheng et al., 2016). Two mechanisms could explain the lower Cd uptake and translocation in $\mathrm{NH}_{4}{ }^{+}$-irrigated plants: first, the rapid assimilation of ammonium in the roots, necessary to avoid this cation toxicity, would allow a greater sequestration of the metal by amino acids inside root vacuoles, thus diminishing its translocation by xylem (Yang et al., 2016), second, lower expression of cadmium transporters in the xylem of $\mathrm{NH}_{4}{ }^{+}$-fed plants, as proposed by Hu et al. (2013), which would also result in lower $\mathrm{Cd}$ accumulation in shoots. In addition, less $\mathrm{Cd}$ translocated to shoots represents an advantage for edible plants, reducing the potencial health risk of this toxic element.

It is supposed that $\mathrm{Cd}$, as well as other heavy metals, are taken by plants through transporters of essential elements (Gojon and Gaymard, 2010). In that way, Cd can be translocated to the leaves and accumulated in aerial plant tissues, resulting in severe growth inhibition and macro and micronutrient imbalances. In this study, no significant changes in leaf iron concentration was observed neither in the leaves nor in the roots of Cd-treated plants, regardless of the nitrogen source. Similar results were reported by Smeets et al. (2008) in 3-week old Arabidopsis plants treated with 5-20 $\mu \mathrm{M} \mathrm{CdSO}_{4}$. Luo et al. (2012) found greater iron uptake by roots of tomato plants fed with $\mathrm{NO}_{3}{ }^{-}$, but the iron content in the shoots did not vary. The lower cadmium accumulation observed in $\mathrm{NH}_{4}{ }^{+}$-fed tomato plants compared to $\mathrm{NO}_{3}{ }^{-}$-fed ones by Luo et al. (2012) was related to a lower expression of the iron transporter IRT1. In spite of this, our results were not in the direction to the idea of competition between $\mathrm{Cd}$ and $\mathrm{Fe}$ for entry in plants through iron root transporters, as no significant changes in Fe contents were found on comparing Cd- and $\mathrm{Cd}+$ treatments in Arabidopsis plants.

According to different reports, the effect of Cd on chlorophyll depends on the plant species, the metal concentration, and, sometimes, on the nitrogen source present in the grown medium. In our experimental system, cadmium reduced chlorophyll content independently of the nitrogen source; however, plants grown without cadmium showed even lower chlorophyll levels when nitrate was the only nitrogen form provided. In this regard, it has been reported that rice plants grown in $\mathrm{NH}_{4}{ }^{+}$as sole nitrogen source showed chlorophyll levels significantly higher than those of $\mathrm{NO}_{3}{ }^{-}$-fed plants (Hassan et al., 2008, 2005), but no significant difference in chlorophyll content was observed between $\mathrm{NH}_{4}{ }^{+}$and $\mathrm{NH}_{4} \mathrm{NO}_{3}{ }^{-}$fed plants when they were exposed to $1 \mu \mathrm{M} \mathrm{Cd}$. Zhou et al. (2011) reported that cucumber plants grown under $\mathrm{NH}_{4}{ }^{+}$nutrition showed decreased plant growth, net photosynthetic rate and maximum photochemical efficiency of photosystem II compared to $\mathrm{NO}_{3}{ }^{-}$-grown plants, whereas these parameters were not affected in rice plants grown either with nitrate or ammonium as the $\mathrm{N}$ source. In our study, PSII quantum yield decayed in NA + Cd and A + Cd compared to plants grown without $\mathrm{Cd}$. Our findings indicate that in the absence of $\mathrm{Cd}$, Arabidopsis plants prefer NA source over ammonium as N source, being in these conditions able to couple the photosynthetic electron transport and chlorophyll synthesis to $\mathrm{NO}_{3}{ }^{-}$assimilation.

Although $\mathrm{Cd}$ is not a redox-active metal, it can indirectly generate ROS disturbing the antioxidative systems and electron transport chains or inducing lipid peroxidation (Anjum et al., 2013). In our experimental conditions, no signs of oxidative damage in terms of lipid peroxidation were observed independently of the nitrogen source (data not shown) possibly because a very strong increase in GPOX activity as well as in proline and anthocyanins levels, and in $\mathrm{F} 3 \mathrm{H}$ gene expression occurred in all Cd-treated plants, suggesting a general response against $\mathrm{Cd}$ toxicity, attempting to avoid oxidative damage. Increased activities for GPOX, syringaldazine peroxidase, and ascorbate peroxidase were observed in A. thaliana leaves after exposure to increasing $\mathrm{CdSO}_{4}$ concentrations, without changes in other antioxidant enzymes such as catalase and superoxide dismutase, denoting a fundamental role of peroxidases against oxidative damage (Smeets et al., 2008). Proline accumulation in plants is related to the adaptive response against abiotic stresses, including those caused by heavy metals (Yang et al., 2016). High proline levels in response to Cd stress has also been reported in several species, as tomato (Alves et al., 2017) or Solanum nigrum (Al Khateeb and Al-Qwasemeh, 2014). Another mechanism through which plants can restrict heavy metal toxicity is by increased synthesis of flavonoids and anthocyanins, which can act as free radical scavengers (Korkina, 2007; Michalak, 2006). These compounds are able to scavenge ROS (Nowak and Gawlik-Dzikib, 2007), have a great potential to chelate Cd in cell walls (Manquián-Cerda et al., 2018) and are accumulated in several plant species subjected to diverse metals (Díaz et al., 2001; Winkel-Shirley, 2002). The visible purple color in the rosette leaves of Arabidopsis plants exposed to cadmium corresponded to an increased level of anthocyanins in all Cd-treated plants compared to their controls without the metal. Ammonium-fed plants, either with or without Cd addition, presented the highest levels of anthocyanins, that coupled to a higher proline content, offered an additional protective mechanism against oxidative stress in these plants compared to $\mathrm{N}$-fed plants.

In addition to the effect that the nitrogen source has on cadmium accumulation, the metal has also an impact on nitrate uptake and concentration. As it has been reported by several authors in different plant species (Hernández et al., 1997; Wang et al., 2008; Mao et al., 2014), in our experimental system, cadmium treatment significantly reduced nitrate levels in NA and $\mathrm{N}$-fed plants. This reduction could be related to a reduce uptake and transport of $\mathrm{NO}_{3}{ }^{-}$by the inhibition of NRT1.1 transporter, as it was observed in Arabidopsis by Mao et al. (2014). The question arises as to whether the inhibition of the nitrate transporter by cadmium increases the toxicity of the metal, since, as it was reported by Zhu et al. (2019) in Arabidopsis, the stimulation of NRT1.1 transporter by $\mathrm{Pb}_{2}{ }^{+}$increases nitrate uptake with the consumption of rizospheric $\mathrm{H}^{+}$by root cells thus reducing $\mathrm{Pb}_{2}{ }^{+}$bioavailability and its uptake by the plant.

It is well known that the majority of $\mathrm{NO}_{3}{ }^{-}$absorbed by plants is translocated and undergoes reductive assimilation in the shoot. We hypothesize that $\mathrm{Cd}$ alters $\mathrm{NO}_{3}{ }^{-}$normal translocation to the aerial parts, thus impairing the nitrogen assimilatory pathway, limiting the influx of the anion and the further translocation to the shoots, as reported by other authors (Loque et al., 2003; Vidmar et al., 2000). Zhang et al. (2014b) demonstrated that $\mathrm{Cd}$ stress induced $\mathrm{NO}_{3}{ }^{-}$allocation to roots in Arabidopsis thaliana, in accordance to the response observed in our experimental conditions where roots accumulated much more nitrates than leaves when the nitrogen source was nitrate. This may be an adaptive mechanism of plant tolerance to heavy metals because $\mathrm{NO}_{3}{ }^{-}$ allocation to roots may help to compensate for the impaired function of photosystem II in leaves of plants supplied with Cd, as suggested by de Sousa Leite and Monteiro (2019). Ammonium levels raised in the roots 
of Arabidopsis under NA $+\mathrm{Cd}$ and $\mathrm{N}+\mathrm{Cd}$ treatments but remained unchanged in the roots of A-Cd-treated plants respect to the control without $\mathrm{Cd}$. The high $\mathrm{NH}_{4}{ }^{+}$concentration observed in the leaves of plants supplied with ammonium can be mainly attributed to the great availability of this ionic form in the nutrient solution, but in the case of NA-Cd and N-Cd, other mechanisms such as increased glutamine synthase (GS) activity or increased proteolysis should be considered.

A gene encoding a nitrate transporter involved in the unloading of nitrate from the xylem sap, AtNRT1.8, was strongly stimulated by $\mathrm{Cd}^{2+}$ provision. When the nrt1.8-1 mutant was grown on a medium containing both nitrate and $\mathrm{Cd}^{2+}$, increased sensitivity to $\mathrm{Cd}^{2+}$ toxicity compared to wild-type plants was observed (Li et al., 2010). Many reports suggest that AtNRT1.8 mediates $\mathrm{Cd}^{2+}$ tolerance because it restricts nitrate translocation to shoots in response to $\mathrm{Cd}^{2+}$, thus playing a crucial role in protecting Arabidopsis from cadmium toxicity, and possibly against a wide range of biotic and abiotic stresses (Li et al., 2010). Therefore, it can be speculated that nitrate retention in the roots may be a signal to increase nitrate assimilation in this organ and, simultaneously, to reduce Cd toxicity.

The attenuation of $\mathrm{NO}_{3}{ }^{-}$levels and other direct or indirect effects of Cd on NR would result in a decline in the activity of NR (Boominathan and Doran, 2003). In this work, it has been shown that cadmium reduced nitrate contents, as well as NR activity, compared to plants grown in solutions devoid of $\mathrm{Cd}$, in accordance with that reported for maize (Rizzardo et al., 2012) or Solanum nigrum (Wang et al., 2008). Cadmium also reduced nitrates accumulation and inhibited NR activity in roots and shoots of rice (Hassan et al., 2008). In this case, the effect was dependent on the nitrogen source, being ammonium fed-plants less affected. In higher plants, $\mathrm{NO}_{3}{ }^{-}$exposure is known to induce the transcription of genes encoding NR (Stitt, 1999). A close relationship between NR activity and AtNIA1 or AtNIA2 transcript levels was observed in the present study, with a significant downregulation of NR genes and NR activity upon Cd addition, except for A-fed plants, where Cd inhibited NR activity and downregulated NIA2 but greatly upregulated NIA1. The correlation between NR activity and NIA2 expression was supported by the fact that the nitrate reductase codified by NIA2 is responsible for the $90 \%$ of the enzyme activity in leaves (Wilkinson and Crawford, 1993), so the induction of NIA1 gene expression in $\mathrm{NH}_{4}{ }^{+}$ medium, was not enough to compensate NIA2 gene reduced expression and did not compensate for NR activity. To our knowledge, this is the first report studying the correlation of NIA genes expression and NR activity upon Cd exposure in Arabidopsis plants cultivated under different nitrogen sources.

The results presented in this work showed that different $\mathrm{N}$ sources did not influence the tolerance to $\mathrm{Cd}$. However, our results on $\mathrm{Cd}$ partitioning in plants showed a different allocation of Cd in $\mathrm{N}$ or A-fed plants, suggesting that different mechanisms of response to $\mathrm{Cd}$ operated under both nitrogen sources. Moreover, A-Cd plants not only accumulated lower Cd levels in roots and shoots but also had increased amount of proline and anthocyanins, both protective compounds that means an advantage to fight against metal toxicity-induced oxidative stress.

\section{Conclusions}

In the present work, it is shown that Cd uptake, translocation, and accumulation in Arabidopsis tissues are affected by the predominant chemical form of nitrogen available. This result has advantage and disadvantages. On one hand, despite the lower Cd content in the entire plant when $\mathrm{NH}_{4}{ }^{+}$is supplied, metal damage to plant growth could not be avoided, probably due to a synergistic action of $\mathrm{Cd}$ with ammonium. On the other hand, $\mathrm{NH}_{4}{ }^{+}$supplied as the sole $\mathrm{N}$ source significantly reduced cadmium accumulation in plant tissues and allow the metal retention in roots preferentially over the shoots. This could be an effective metabolic strategy to diminish the toxicity of the metal in the aboveground parts and also an advantage if edible plants are cultivated to use the aerial parts as food.
Concerning the application of $\mathrm{NH}_{4}{ }^{+}$-based fertilizers as a tool for phytoremediation of polluted soils, ammonium would not potentially favor phytoextraction of $\mathrm{Cd}$ from soils. In spite for this, the high proline and anthocyanin levels observed in ammonium-fed plants and the comparable tolerance to $\mathrm{Cd}$ toxicity respect to $\mathrm{N}$-fed plants presents an interesting point of study to be applied to other plant species with higher phytoremediation potential and may be more important that the lower accumulating capacity. Further investigation is necessary to better understand the mechanisms and the physiological significance of this adaptive response.

\section{Authors contribution section}

Analía Vazquez, Laura Recalde: Conceptualization, Methodology, Investigation. Andrea V. Cabrera: Methodology. María D. Groppa: Investigation, Visualization; Supervision, Writing - review and editing. María P. Benavides: Conceptualization, Resources, Supervision; Writing - original draft, Writing - review and editing.

\section{Declaration of competing interest}

The authors declare that they have no conflict of interest.

\section{Acknowledgments}

This work was funded by the University of Buenos Aires (UBACYT 20020130100178BA) and Consejo Nacional de Investigaciones Científicas y Técnicas (CONICET,PIP 266). Benavides MP, Groppa MD are researchers of the Consejo Nacional de Investigaciones Científicas y Técnicas (CONICET) and University of Buenos Aires. Analía Vazquez is a fellow from CONICET. Laura Recalde and Andrea Cabrera are fellows from the University of Buenos Aires.

We are grateful to Myriam Zawoznik for the helpful discussions and English correction and to María Gabriela Cano and Eduardo Tambussi, INFIVE-CONICET for the PS II measurements.

\section{References}

Al Khateeb, W., Al-Qwasemeh, H., 2014. Cadmium, copper and zinc toxicity effects on growth, proline content and genetic stability of Solanum nigrum L., a crop wild relative for tomato; comparative study. Physiol. Mol. Biol. Plants 20, 31-39. https:// doi.org/10.1007/s12298-013-0211-5.

Alpha, J.M., Chen, J., Zhang, G., 2009. Effect of nitrogen fertilizer forms on growth, photosynthesis, and yield of rice under cadmium stress. J. Plant Nutr. 32, 306e317. https://doi.org/10.1080/01904160802608635.

Alves, L.R., Monteiro, C.C., Carvalho, R.F., Ribeiro, P.C., Tezotto, T., Azevedo, R.A Gratão, P.L., 2017. Cadmium stress related to root-to-shoot communication depends on ethylene and auxin in tomato plants. Environ. Exp. Bot. 134, 102-115. https://doi. org/10.1016/J.ENVEXPBOT.2016.11.008.

Anjum, N.A., Ahmad, I., Rodrigues, S.M., Henriques, B., Cruz, N., Coelho, C., Pacheco, M., Duarte, A.C., Pereira, E., 2013. Eriophorum angustifolium and Lolium perenne metabolic adaptations to metals- and metalloids-induced anomalies in the vicinity of a chemical industrial complex. Environ. Sci. Pollut. Res. 20, 568-581. https://doi.org/10.1007/ s11356-012-1062-2.

Bates, L.S., Waldren, R.P., Teare, I.D., 1973. Rapid determination of free proline for water-stress studies. Plant Soil 39, 205-207. https://doi.org/10.1007/BF00018060.

Benbrahim-Tallaa, L., Liu, J., Webber, M.M., Waalkes, M.P., 2007. Estrogen signaling and disruption of androgen metabolism in acquired androgen-independence during cadmium carcinogenesis in human prostate epithelial cells. Prostate 67, 135-145. https://doi.org/10.1002/pros.20479.

Boominathan, R., Doran, P.M., 2003. Cadmium tolerance and antioxidative defenses in hairy roots of the cadmium hyperaccumulator. Thlaspi caerulescens. Biotechnol. Bioeng. 83, 158-167. https://doi.org/10.1002/bit.10656.

Cataldo, D.A., Maroon, M., Schrader, L.E., Youngs, V.L., 1975. Rapid colorimetric determination of nitrate in plant tissue by nitration of salicylic acid. Commun. Soil Sci. Plant Anal. 6, 71-80. https://doi.org/10.1080/00103627509366547.

Cheng, M., Wang, P., Kopittke, P.M., Wang, A., Sale, P.W.G., Tang, C., 2016. Cadmium accumulation is enhanced by ammonium compared to nitrate in two hyperaccumulators, without affecting speciation. J. Exp. Bot. 67, 5041-5050. https://doi. org/10.1093/jxb/erw270.

Clemens, S., 2006. Toxic metal accumulation, responses to exposure and mechanisms of tolerance in plants. Biochimie 88, 1707-1719. https://doi.org/10.1016/j.biochi. 2006.07.003.

de Sousa Leite, T., Monteiro, F.A., 2019. Nitrogen form regulates cadmium uptake and accumulation in Tanzania guinea grass used for phytoextraction. Chemosphere 236, 1-9. https://doi.org/10.1016/j.chemosphere.2019.07.055. 
Díaz, J., Bernal, A., Pomar, F., Merino, F., 2001. Induction of shikimate dehydrogenase and peroxidase in pepper (Capsicum annuum L.) seedlings in response to copper stress and its relation to lignification. Plant Sci. 161, 179-188.

Gallego, S.M., Pena, L.B., Barcia, R.A., Azpilicueta, C.E., Iannone, M.F., Rosales, E.P., Zawoznik, M.S., Groppa, M.D., Benavides, M.P., 2012. Unravelling cadmium toxicity and tolerance in plants: insight into regulatory mechanisms. Environ. Exp. Bot. 83, 33-46. https://doi.org/10.1016/J.ENVEXPBOT.2012.04.006.

Gojon, A., Gaymard, F., 2010. Keeping nitrate in the roots: an unexpected requirement for cadmium tolerance in plants. J. Mol. Cell Biol. 2, 299-301. https://doi.org/10.1093/ $\mathrm{jmcb} / \mathrm{mjq} 019$.

Gussarson, M., Asp, H., Adalsteinsson, S., Jensén, P., 1996. Enhancement of Cd effects on growth and nutrient composition of birch (Betula pendula) by buthionine sulphoxinine (BSO). J Exp Bot 47, 211-215.

Hachiya, T., Watanabe, C.K., Fujimoto, M., Ishikawa, T., Takahara, K., Kawai-Yamada, M., Uchimiya, H., Uesono, Y., Terashima, I., Noguchi, K., 2012. Nitrate addition alleviates ammonium toxicity without lessening ammonium accumulation, organic acid depletion and inorganic cation depletion in Arabidopsis thaliana shoots. Plant Cell Physiol. 53 (3), 577-591.

Hassan, M.J., Wang, F., Ali, S., Zhang, G., 2005. Toxic effect of cadmium on rice as affected by nitrogen fertilizer form. Plant Soil 277, 359-365. https://doi.org/10.1007/ s11104-005-8160-6.

Hassan, M.J., Zhang, G., Zhu, Z., 2008. Influence of cadmium toxicity on plant growth and nitrogen uptake in rice as affected by nitrogen form. J. Plant Nutr. 31, 251-262. https://doi.org/10.1080/01904160701853753.

Heath, R.L., Packer, L., 1968. Photoperoxidation in isolated chloroplasts: I. Kinetics and stoichiometry of fatty acid peroxidation. Arch. Biochem. Biophys. 125, 189-198. https://doi.org/10.1016/0003-9861(68)90654-1.

Hernández, L.E., Gárate, A., Carpena-Ruiz, R., 1997. Effects of cadmium on the uptake, distribution and assimilation of nitrate in Pisum sativum. Plant Soil 189, 97-106. https://doi.org/10.1023/A:1004252816355.

Hu, P., Yin, Y.-G., Ishikawa, S., Suzui, N., Kawachi, N., Fujimaki, S., Igura, M., Yuan, C., Huang, J., Li, Z., Makino, T., Luo, Y., Christie, P., Wu, L., 2013. Nitrate facilitates cadmium uptake, transport and accumulation in the hyperaccumulator Sedum plumbizincicola. Environ. Sci. Pollut. Res. 20, 6306-6316. https://doi.org/10.1007/ s11356-013-1680-3.

Jeong, J., Guerinot, M.L., 2009. Homing in on iron homeostasis in plants. Trends Plant Sci. 14, 280-285. https://doi.org/10.1016/j.tplants.2009.02.006.

Korkina, L.G., 2007. Phenylpropanoids as naturally occurring antioxidants: from plant defense to human health. Cell. Mol. Biol. (Noisy-Le-Grand) 53, 15-25.

Lee, J., Durst, R.W., Wrolstad, R.E., 2005. Determination of total monomeric anthocyanin pigment content of fruit juices, beverages, natural colorants, and wines by the $\mathrm{pH}$ differential method: collaborative study. J. AOAC Int. 88, 1269-1278.

Li, J.-Y., Fu, Y.-L., Pike, S.M., Bao, J., Tian, W., Zhang, Y., Chen, C.-Z., Zhang, Y., Li, H.M., Huang, J., Li, L.-G., Schroeder, J.I., Gassmann, W., Gong, J.-M., 2010. The Arabidopsis nitrate transporter NRT1.8 functions in nitrate removal from the xylem sap and mediates cadmium tolerance. Plant Cell line 22, 1633-1646. https://doi.org/ 10.1105/tpc.110.075242.

Loque, D., Tillard, P., Gojon, A., Lepetit, M., 2003. Gene expression of the NO3- transporter NRT1.1 and the nitrate reductase NIA1 is repressed in Arabidopsis roots by NO2-, the product of NO3- reduction. Plant Physiol. 132, 958-967. https://doi.org/ 10.1104/pp.102.018523.

Lu, Y.X., Li, C.J., Zhang, F.S., 2005. Transpiration, potassium uptake and flow in tobacco as affected by nitrogen forms and nutrient levels. Ann. Bot. 95, 991-998. https://doi. org/10.1093/aob/mci104.

Luo, B.F., Du, S.T., Lu, K.X., Liu, W.J., Lin, X.Y., Jin, C.W., 2012. Iron uptake system mediates nitrate-facilitated cadmium accumulation in tomato (Solanum lycopersicum) plants. J. Exp. Bot. 63, 3127-3136. https://doi.org/10.1093/jxb/ers036.

Lux, A., Martinka, M., Vaculik, M., White, P.J., 2011. Root responses to cadmium in the rhizosphere: a review. J. Exp. Bot. 62, 21-37. https://doi.org/10.1093/jxb/erq281.

Maehly, A.C., Chance, B., 1954. The assay of catalases and peroxidases. Methods Biochem. Anal. 1, 357-424.

Maier, N.A., McLaughlin, M.J., Heap, M., Butt, M., Smart, M.K., 2002. Effect of currentseason application of calcitic lime and phosphorus fertilization on soil $\mathrm{pH}$, potato growth, yield, dry matter content, and cadmium concentration. Commun. Soil Sci. Plant Anal. 33, 2145-2165. https://doi.org/10.1081/CSS-120005754.

Manquián-Cerda, K., Cruces, E., Escudey, M., Zúñiga, G., Calderón, R., 2018. Antioxidant enzyme activity and oxidative stress in blueberry (Vaccinium corymbosum L.) plantlets cultivated in vitro. Ecotoxicol. Environ. Saf. 150, 320-326. https://doi.org/10.1016/ j.ecoenv.2017.12.050.

Mao, Q.Q., Guan, M.Y., Lu, K.X., Du, S.T., Fan, S.K., Ye, Y.-Q., Lin, X.Y., Jin, C.W., 2014. Inhibition of nitrate transporter 1.1-controlled nitrate uptake reduces cadmium uptake in Arabidopsis. Plant Physiol. 166, 934-944. https://doi.org/10.1104/pp.114. 243766.

Marchiol, L., Assolari, S., Sacco, P., Zerbi, G., 2004. Phytoextraction of heavy metals by canola (Brassica napus) and radish (Raphanus sativus) grown on multicontaminated soil. Environ. Pollut. 132, 21-27. https://doi.org/10.1016/j.envpol.2004.04.001.

Marschner, H., Marschner, P., 2012. Marschner's Mineral Nutrition of Higher Plants. Academic Press.

McClure, P.R., Kochian, L.V., Spanswick, R.M., Shaff, J.E., 1998. Evidence for cotransport of nitrate and protons in maize roots I. Effects of nitrate on the membrane potential. Plant Physiol. 93, 281-289. https://doi.org/10.1104/pp.93.1.281.

Michalak, A., 2006. Phenolic compounds and their antioxidant activity in plants growing under heavy metal stress WWW Document. Pol. J. Environ. Stud (accessed 5.22.2018). https://www.pjoes.com/abstracts/2006/Vol15/No04/01.html.

Nasraoui-Hajaji, A., Gouia, H., Carrayol, E., Haouari-Chaffei, C., 2012. Ammonium alleviates redox state in Solanum seedlings under cadmium stress conditions. 02. J.
Environ. Anal. Toxicol. 1-6. https://doi.org/10.4172/2161-0525.1000141.

Nazar, R., Iqbal, N., Masood, A., Khan, M.I.R., Syeed, S., Khan, N.A., 2012. Cadmium toxicity in plants and role of mineral nutrients in its alleviation. 03. Am. J. Plant Sci. 1476-1489. https://doi.org/10.4236/ajps.2012.310178.

Nowak, R., Gawlik-Dzikib, U., 2007. Polyphenols of Rosa L. leaves extracts and their radical scavenging activity. Z. Naturforschung 62, 32-38.

Rabêlo, F.H.S., Lux, A., Rossi, M.L., Pinheiro Martinelli, A., Cuypers, A., Lavres, J., 2018. Adequate S supply reduces the damage of high Cd exposure in roots and increases $\mathrm{N}$, $\mathrm{S}$ and $\mathrm{Mn}$ uptake by Massai grass grown in hydroponics. Environ. Exp. Bot. 148, 35-46. https://doi.org/10.1016/j.envexpbot.2018.01.005.

Ramachandran, V., D'Souza, T.J., 2002. Plant uptake of cadmium, zinc, and manganese from four contrasting soils amended with Cd-enriched sewage sludge. J. Environ. Sci. Heal. Part A 37, 1337-1346. https://doi.org/10.1081/ESE-120005990.

Rayar, A., Hai, T., 1977. Effect of ammonium on uptake of phosphorus, potassium, calcium and magnesium by intact soybean plants. Plant Soil. https://doi.org/10.2307/ 42947106.

Rizzardo, C., Tomasi, N., Monte, R., Varanini, Z., Nocito, F.F., Cesco, S., Pinton, R., 2012 Cadmium inhibits the induction of high-affinity nitrate uptake in maize (Zea mays L.) roots. Planta 236, 1701-1712. https://doi.org/10.1007/s00425-012-1729-4.

Roth, U., von Roepenack-Lahaye, E., Clemens, S., 2006. Proteome changes in Arabidopsis thaliana roots upon exposure to $\mathrm{Cd}^{2+}$. J. Exp. Bot. 57, 4003-4013. https://doi.org/ 10.1093/jxb/erl170.

Salt, D.E., Smith, R.D., Raskin, I., 1998. Phytoremediation. Annu. Rev. Plant Physiol. 49, 643-668.

Sarwar, N., Saifullah Malhi, S.S., Zia, M.H., Naeem, A., Bibi, S., Farid, G., 2010. Role of mineral nutrition in minimizing cadmium accumulation by plants. J. Sci. Food Agric 90, n/a. https://doi.org/10.1002/jsfa.3916.

Savidov, N.A., Tokarev, B.I., Lips, S.H., 1997. Regulation of Mo-cofactor, NADH-and NAD (P)H-specific nitrate reductase activities in the wild type and two nar-mutant lines of barley (Hordeum vulgare L.). J. Exp. Bot. 48, 847-855.

Smeets, K., Ruytinx, J., Semane, B., Van Belleghem, F., Remans, T., Van Sanden, S., Vangronsveld, J., Cuypers, A., 2008. Cadmium-induced transcriptional and enzymatic alterations related to oxidative stress. Environ. Exp. Bot. 63, 1-8. https://doi. org/10.1016/j.envexpbot.2007.10.028.

Stitt, M., 1999. Nitrate regulation of metabolism and growth. Curr. Opin. Plant Biol. 2, $178-186$.

Taiz, L., Zeiger, E., Møller, I.M., Murphy, A., 2014. Plant Physiology and Development, sixth ed. Sinauer Associates, Inc, Sunderland.

Tlustoš, P., Száková, J., Kořínek, K., Pavlíková, D., Hanč, A., Balík, H., 2006. The effect of liming on cadmium, lead, and zinc uptake reduction by spring wheat grown in contaminated soil. Plant Soil Environ. 52, 16-24.

Uraguchi, S., Fujiwara, T., 2013. Rice breaks ground for cadmium-free cereals. Curr. Opin. Plant Biol. 16, 328-334. https://doi.org/10.1016/J.PBI.2013.03.012.

Vidmar, J.J., Zhuo, D., Siddiqi, M.Y., Schjoerring, J.K., Touraine, B., Glass, A.D., 2000. Regulation of high-affinity nitrate transporter genes and high-affinity nitrate influx by nitrogen pools in roots of barley. Plant Physiol. 123, 307-318.

Wang, L., Zhou, Q., Ding, L., Sun, Y., 2008. Effect of cadmium toxicity on nitrogen metabolism in leaves of Solanum nigrum L. as a newly found cadmium hyperaccumulator. J. Hazard Mater. 154, 818-825. https://doi.org/10.1016/j.jhazmat. 2007.10.097.

Wångstrand, H., Eriksson, J., Öborn, I., 2007. Cadmium concentration in winter wheat as affected by nitrogen fertilization. Eur. J. Agron. 26, 209-214. https://doi.org/10. 1016/J.EJA. 2006.09.010.

Wilkinson, J.Q., Crawford, N.M., 1993. Identification and characterization of a chlorateresistant mutant of Arabidopsis thaliana with mutations in both nitrate reductase structural genes NIA1 and NIA2. Mol. Gen. Genet. MGG 239, 289-297. https://doi. org/10.1007/bf00281630.

Winkel-Shirley, B., 2002. Biosynthesis of flavonoids and effects of stress. Curr. Opin. Plant Biol. 5, 218-223. https://doi.org/10.1016/S1369-5266(02)00256-X.

Wintermans, J.F.G.M., De Mots, A., 1965. Spectrophotometric characteristics of chlorophylls $\mathrm{a}$ and $\mathrm{b}$ and their phenophytins in ethanol. Biochim. Biophys. Acta (BBA) Biophys. Incl. Photosynth. 109, 448-453. https://doi.org/10.1016/0926-6585(65) 90170-6.

Xie, H.L., Jiang, R.F., Zhang, F.S., McGrath, S.P., Zhao, F.J., 2009. Effect of nitrogen form on the rhizosphere dynamics and uptake of cadmium and zinc by the hyperaccumulator Thlaspi caerulescens. Plant Soil 318, 205-215. https://doi.org/10.1007/ s11104-008-9830-y.

Yaneva, I.A., Hoffmann, G.W., Tischner, R., 2002. Nitrate reductase from winter wheat leaves is activated at low temperature via protein dephosphorylation. Physiol. Plant 114, 65-72.

Yang, G., Wang, C., Wang, Y., Guo, Y., Zhao, Y., Yang, C., Gao, C., 2016. Overexpression of ThVHAc1 and its potential upstream regulator, ThWRKY7, improved plant tolerance of cadmium stress. Sci. Rep. 6, 18752. https://doi.org/10.1038/srep18752.

Zhang, F., Wan, X., Zhong, Y., 2014. Nitrogen as an important detoxification factor to cadmium stress in poplar plants. J. Plant Interact. 9 (1), 249-258.

Zhang, G.B., Yi, H.Y., Gong, J.M., 2014. The Arabidopsis ethylene/jasmonic acid-NRT signaling module coordinates nitrate reallocation and the trade-off between growth and environmental adaptation. Plant Cell 26, 3984e3998. https://doi.org/10.1105/ tpc.114.129296.

Zhou, Y., Zhang, Y., Wang, X., Cui, J., Xia, X., Shi, K., Yu, J., 2011. Effects of nitrogen form on growth, $\mathrm{CO}_{2}$ assimilation, chlorophyll fluorescence, and photosynthetic electron allocation in cucumber and rice plants. J. Zhejiang Univ. - Sci. B 12, 126-134. https://doi.org/10.1631/jzus.B1000059.

Zhu, J., Fang, X.Z., Dai, Y.J., Zhu, Y.X., Chen, H.S., Lin, X.Y., Jin, C.W., 2019. Nitrate transporter 1.1 alleviates lead toxicity in Arabidopsis by preventing rhizosphere acidification. J. Exp. Bot. 70 (21), 6363-6374. 